\title{
Utilization of Indonesia's Hot Spring Sources for Electricity using Kalina Cycle and Organic Rankine Cycle
}

\author{
Grano Prabumukti ${ }^{1 *}$, Widodo Wahyu Purwanto ${ }^{1}$ \\ ${ }^{1}$ Department of Chemical Engineering, Faculty of Engineering, Universitas Indonesia, Depok - Indonesia
}

\begin{abstract}
Indonesia posses $40 \%$ of the world's geothermal energy sources. The existence of hydrothermal sources is usually characterized by their surface manifestations such as hot springs, geysers and fumarole. Hot spring has a potential to be used as a heat source to generate electricity especially in a rural and isolated area. Hot springs can be converted into electricity by binary thermodynamic cycles such as Kalina cycle and ORC. The aim of this study is to obtain the best performances of cycle configuration and the potential power capacity. Simulation is conducted using UNISIM software with working fluid and its operating condition as the decision variables. The simulation result shows that R1234yf and propene with simple ORC as desired working fluid and cycle configuration. It reaches a maximum thermal efficiency up to $9.6 \%$ with a specific turbine inlet pressure. Higher temperature heat source will result a higher thermal efficiency.. Cycle thermal efficiency varies from $4.7 \%$ to $9.6 \%$ depends on source of hot spring temperature. Power capacity that can be generated using Indonesia's hot spring is ranged from $2 \mathrm{kWe}$ to $61.2 \mathrm{kWe}$. The highest capacity located in Kawah Sirung and the least located in Kaendi.
\end{abstract}

\section{Introduction}

Indonesia is one of the world's richest geothermal reserves, with $40 \%$ of the world's geothermal potential. However, its current utilization is only $4.1 \%$ of its total potential. Geothermal systems in Indonesia are generally hydrothermal systems with temperatures greater than $225^{\circ} \mathrm{C}$, only a few locations have temperatures between $125-225^{\circ} \mathrm{C}$. The presence of hydrothermal sources in the sub-surface of the earth is usually characterized by surface manifestations such as hot springs, Geysers, fumaroles, mud pools, steaming ground and altered rock. [1]

Hot spring is a kind of heat manifestations which can be used as heat source to generate electricity. Hot spring in Indonesia usually has temperatures below $100^{\circ} \mathrm{C}$. So far, geothermal manifestations in the form of hot spring in Indonesia, only used for use as a hot water bath. A hot spring source can be utilized to build a smallscale power plants by using binary cycles. [1]

Organic Rankine Cycle (ORC) power plant in commercial scale using the hot springs has been conducted in several countries. Holdmann was reporting ORC in Chena Hot Spring, Alaska, geothermal heat sources with temperatures $73^{\circ} \mathrm{C}$, the working fluid $\mathrm{R} 134 \mathrm{a}$, water cooling fluid temperature $4.4^{\circ} \mathrm{C}$, can produce a capacity of $210 \mathrm{kWe}$ and an efficiency of $8.2 \%$ [2].

The working fluid used in binary generation systems, is a working fluid with a lower boiling point than water. The heat source with low temperature causes the thermodynamic efficiency of this cycle to be low. [3]

The purpose of this study is to obtain the maximum cycle efficiency for typical hot spring temperature range and its power capacity. The cycles assessed in this study are Kalina cycle with KCS11 type, simple ORC cycle and dual pressure ORC. The working fluids which is considered in this study are propane, propene, R1234yf, R407afor ORC and ammonia $85 \%$ for Kalina cycle. Heat source used is a heat source with a temperature of $60^{\circ} \mathrm{C}$ $99^{\circ} \mathrm{C}$. The temperature and flow rate of the hot spring use in the simulation are the average values [1].

\section{Modeling the cycle}

For geothermal systems with low temperatures, the thermal efficiency is ranged between $5 \%-12 \%$. Even the energy efficiency is about $25 \%-50 \%$. Some studies are done to improve the efficiency of binary cycle, depending on the working fluid or a combinations two or more working fluids is employed [4].

*orresponding author: widodo@che.ui.ac.id 


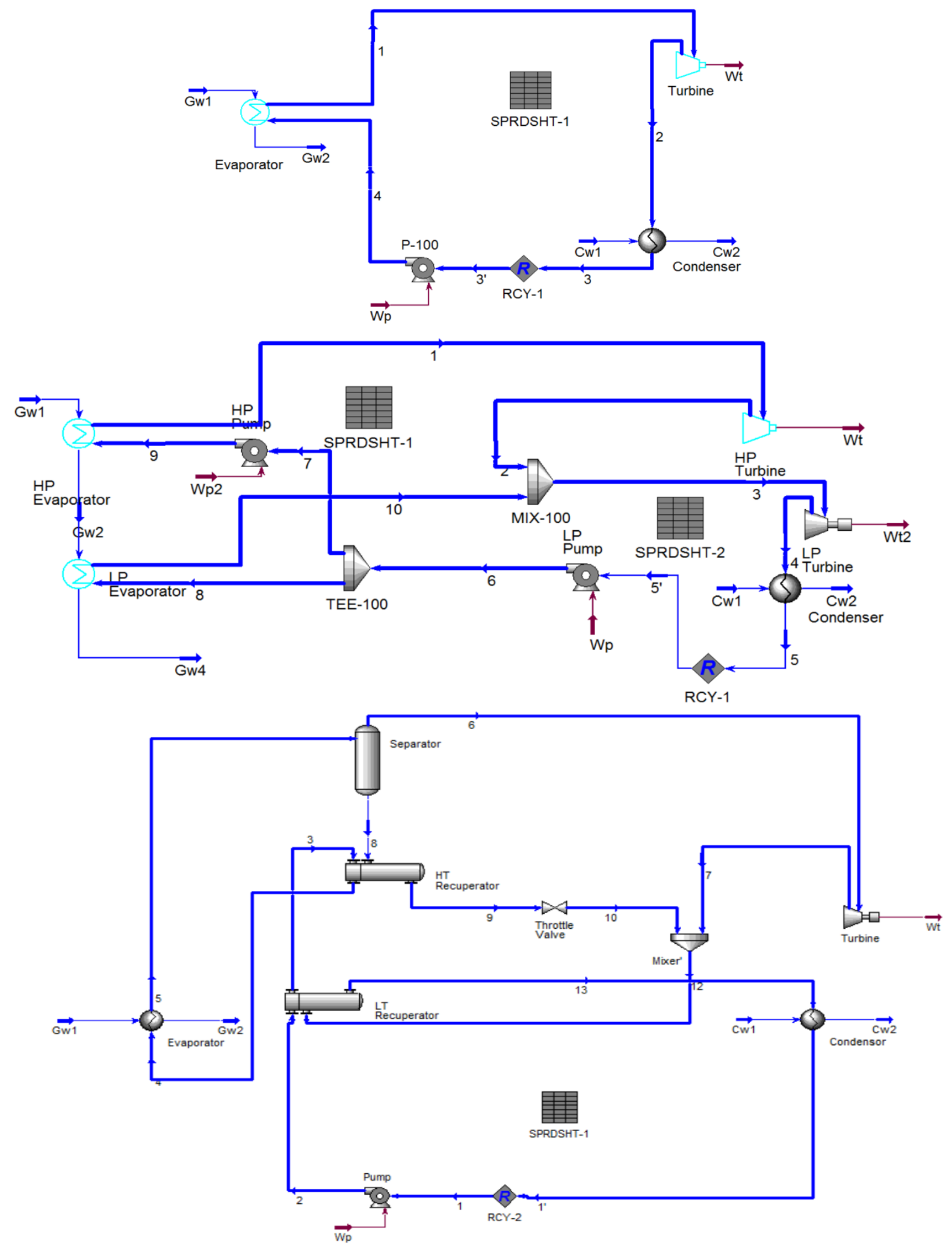

Fig. 1.Simulation scheme for (a) Simple ORC (b) Dual Pressure ORC (c) Kalina Cycle

A simple binary cycle has a low thermal efficiency because of the low temperature difference between the heat source and the temperature at the heat sink. Carnot efficiency is the maximum possible efficiency of cycles that work in two temperature ranges [5].

In a thermodynamic cycle, cooling water is required for the condensation process in the condenser. Cooling water at a source is usually obtained from natural sources such as river or sea water. Normal average air temperature is usually around $25^{\circ} \mathrm{C}[5]$.

In a binary cycle, a heat exchanger is used to exchange heat between heat sources and working fluids. In addition, a heat exchanger is also required on the condenser to condense the working fluid that has passed through the turbine. To support the existence of irreversibility, a heat exchanger is usually having a certain temperature minimum approach. For low 
temperature heat sources, the temperature change in the heat exchanger is usually around $5^{\circ} \mathrm{C} .[6,7]$

One type of thermodynamic cycle commonly used to generate electricity from heat sources with low temperatures is ORC.ORC uses the working fluid with low boiling point, it can convert the working fluid into its vapor phase at a low temperature of heat source. In ORC, there are four main components: Steam Turbine, Pump, Evaporator and Condensor. The main difference between a Rankine cycle and a ORC cycle is in the Rankine cycle use water as the working fluid to produce steam. In ORC, the system use organic working fluid such as a refrigerant or hydrocarbon ORC system use an evaporator as heat absorption equipment so that the cycle does not require burning process, hence it does not produce air pollution. [3]

Figure 1 shows simulation scheme for each cycle. Table 1 shows the assumptions which is used to simplified the modelling of each cycle. The pump efficiency, turbine efficiency and generator efficiency value which is used is a typical efficiency value. The assumptions for cooling water is due to limitation of real world condition. Certain pinch temperature is also used to keep the second law efficiency at certain level.

Table 1. Assumption used in the simulation

\begin{tabular}{|l|c|c|}
\hline \multicolumn{1}{|c|}{ Variable } & $\begin{array}{c}\text { Simple ORC \& } \\
\text { Dual- Pressure } \\
\text { ORC }\end{array}$ & $\begin{array}{c}\text { Kalina } \\
\text { Cycle }\end{array}$ \\
\hline Tcooling water $\left({ }^{\circ} \mathrm{C}\right)$ & 27 & 27 \\
\hline Pump Efficiency $(\%)$ & 80 & 80 \\
\hline Turbine Eficiency $(\%)$ & 85 & 85 \\
\hline $\begin{array}{l}\Delta \text { T Pinch Evaporator } \\
\left({ }^{\circ} \mathrm{C}\right)\end{array}$ & 5 & 5 \\
\hline $\begin{array}{l}\text { Generator Efficiency } \\
(\%)\end{array}$ & 96 & 96 \\
\hline Working fluid & $\begin{array}{c}\text { propane, propene, } \\
\text { R1234yf, R407a }\end{array}$ & $\begin{array}{c}\text { ammonia } \\
85 \%\end{array}$ \\
\hline
\end{tabular}

\subsection{Simple ORC}

In simple ORC, the pressure of the working fluid as it exits the condenser reaches the evaporator pressure with the help of the pump. The working fluid gets heat from the geothermal fluid in the evaporator. After passing the evaporator, the working fluid expands in the turbine to the condenser pressure and is finally cooled by cooling water. The scheme of a Simple ORC can be seen in Figure 1a. A simple ORC is relatively simple and requires less equipment than other cycles. However, this cycle has a great thermodynamic irreversibility due to the large temperature difference in evaporators and condensers. [8]

Table 2 shows energy balance equations of each component of Simple ORC.
Table 2.Equation models of Simple ORC

\begin{tabular}{|c|c|}
\hline Component & Energy Balance Equation \\
\hline Turbine & $W_{t}=m_{1}\left(h_{1}-h_{2}\right)$ \\
\hline Pump & $W_{p}=m_{3},\left(h_{3},-h_{4}\right)$ \\
\hline Condenser & $m_{2}\left(h_{2}-h_{3}\right)=m_{c w 1}\left(h_{c w 1}-h_{c w 2}\right)$ \\
\hline Evaporator & $m_{4}\left(h_{4}-h_{1}\right)=m_{g w 1}\left(h_{g w 1}-h_{g w 2}\right)$ \\
\hline \multicolumn{2}{|c|}{ Cycle Efficiency } \\
\hline \multicolumn{2}{|c|}{$\eta=\left(W_{t}-W_{p}\right) / m_{g w 1}\left(h_{g w 1}-h_{g w 2}\right)$} \\
\hline
\end{tabular}

\subsection{Dual pressure ORC}

The process in a dual pressure ORC system is the same as in the simple ORC. The difference is the overall mass flow rate in the case is divided into two different evaporation pressure level. In series configuration of a dual pressure ORC system this separation occurs after Low Pressure (LP) Pump. Furthermore, the LP flow is evaporated on the low pressure (LP) evaporator while the remaining mass flow rate is pumped to high pressure (HP) pump. The working fluid which passes through the HP Pump is evaporated on high pressure (HP) Evaporator. High pressure working fluid is expanded in HP Turbine and mixes with low pressure fluid output of LP evaporator. Both fluids mix and expand in LP turbine.

The process scheme for dual pressure ORC can be seen in Figure 1c. In this system no recuperator or preheater is used for the cycle. The energy balance for a dual pressure ORC can be seen in the Table 3 .

Table 3.Equation models of Dual Pressure ORC

\begin{tabular}{|c|c|}
\hline Component & Energy Balance Equation \\
\hline HP Turbine & $W_{t}=m_{1}\left(h_{1}-h_{2}\right)$ \\
\hline LP Turbine & $W_{t 2}=m_{3}\left(h_{3}-h_{4}\right)$ \\
\hline HP Pump & $W_{p 2}=m_{7}\left(h_{7}-h_{9}\right)$ \\
\hline LP Pump & $W_{p}=m_{5},\left(h_{5}-h_{6}\right)$ \\
\hline Condenser & $m_{4}\left(h_{4}-h_{5}\right)=m_{c w 1}\left(h_{c w 1}-h_{c w 2}\right)$ \\
\hline HP Evaporator & $m_{9}\left(h_{9}-h_{1}\right)=m_{g w 1}\left(h_{g w 1}-h_{g w 2}\right)$ \\
\hline LP Evaporator & $m_{8}\left(h_{8}-h_{10}\right)=m_{g w 1}\left(h_{g w 1}-h_{g w 2}\right)$ \\
\hline Mixer & $m_{2} h_{2}+m_{10} h_{10}=m_{3} h_{3}$ \\
\hline Splitter & $m_{6} h_{6}=m_{8} h_{8}+m_{7} h_{7}$ \\
\hline \multicolumn{2}{|c|}{ Cycle Efficiency } \\
\hline \multicolumn{2}{|c|}{$\eta=\left(W_{t}-W_{p}\right) / m_{g w 1}\left(h_{g w 1}-h_{g w 2}\right)$} \\
\hline
\end{tabular}

\subsection{Kalina cycle}

For Kalina cycle, the ammonia-water mixture enters the separator after obtaining heat coming from geothermal fluid in the preheater and evaporator. In the separator, the mixture with the saturated vapor enters the turbine and expands to the condenser pressure. Meanwhile, the fluid mixture with the saturated liquid enters High Temperature Recuperator (HTR) to release heat to the 
Low Temperature Recuperator (LTR) fluid. After that, the fluid mixture that has released heat in the HTR, enters the expansion valve and mixes with the turbine output fluid. The mixed fluid is exploited by heat in the LTR to heat the condenser output fluid.

Separator in a Kalina cycle is used to separate the vapor and liquid phase of working fluid that will enter the turbine. The separator output with the liquid phase will have a lower ammonia concentration than the separator output with the vapor phase. The output in the liquid phase will flow into the recuperator to absorb the heat. After passing the recuperator, the liquid phase fluid will enter the expansion valve to lower the pressure before mixed with the working fluid that has passed through the turbine. After mixing, the two working fluids will enter the condenser to produce a liquid phase.

The efficiency of the Kalina cycle is $2.17 \%$ points lower than the ORC baseline, $1.28 \%$ points of the ORC dual-fluid but $0.11 \%$ points higher than the dual-pressure ORC. [10]

In general, with the use of mixed ammonia and water working fluids, the Kalina cycle has an unstable evaporation and condensation temperature. This causes the Carnot efficiency of the Kalina cycle to be better than the ORC cycle. Table 4 shows the energy balance for each equipment in the Kalina cycle.

Table 4.Equation models of Kalina Cycle

\begin{tabular}{|l|l|}
\hline \multicolumn{1}{|c|}{ Component } & Energy Balance Equation \\
\hline Turbine & $W_{t}=m_{8}\left(h_{8}-h_{9}\right)$ \\
\hline Pump & $W_{p}=m_{1}\left(h_{2}-h_{1}\right)$ \\
\hline Condenser & $m_{5}\left(h_{10}-h_{1}\right)=m_{c w 1}\left(h_{c w 1}-h_{c w 2}\right)$ \\
\hline Evaporator & $\left.m_{3}\left(h_{4}-h_{3}\right)=m_{g w 1} h_{g w 1}-h_{g w 2}\right)$ \\
\hline Recuperator & $m_{5}\left(h_{6}-h_{5}\right)=m_{11}\left(h_{11}-h_{12}\right)$ \\
\hline Separator & $m_{7} h_{7}=m_{8} h_{8}+m_{11} h_{11}$ \\
\hline Mixer & $m_{9} h_{9}+m_{13} h_{13}=m_{10} h_{10}$ \\
\hline Throttling Valve & $m_{12} h_{12}=m_{13} h_{13}$ \\
\hline \multicolumn{2}{|r}{ Cycle Efficiency } \\
\hline \multicolumn{2}{|r}{$\eta=\left(W_{t}-W_{p}\right) / m_{g w 1}\left(h_{g w 1}-h_{g w 2}\right)$} \\
\hline
\end{tabular}

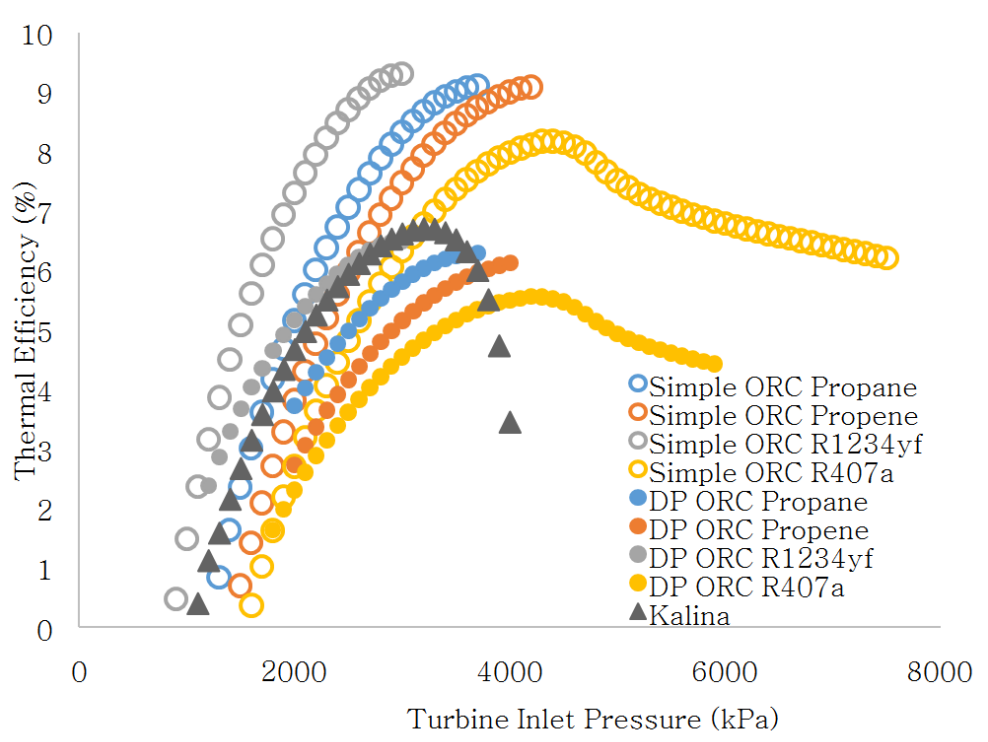

Fig.2. Cycle Efficiency for different Turbine Inlet Pressure

\section{Result and discussion}

\subsection{Turbine Inlet Pressure Variations}

The base case for the simulation is a heat source temperature value of $95^{\circ} \mathrm{C}$ with $50 \mathrm{~kg} / \mathrm{s}$ mass flow rate. The minimum approach used in the evaporator is $5^{\circ} \mathrm{C}$, so the turbine inlet temperature value is $90^{\circ} \mathrm{C}$. Figure 2 shows the influence of turbine input variation on thermal efficiency of the cycle. In general, an increase in turbine inlet pressure will result in increased efficiency. This is because of the greater difference between the enthalpy value of turbine inlet conditions and turbine output. This condition results in a larger $\mathrm{W}_{\text {net }}$ value, so the thermal efficiency value will rise. However, at some point, the efficiency will decrease as the pressure continues to increase. This is because the increase of enthalpy difference value between turbine inlet and outlet condition is not significant. 
For each heat source temperature, an optimum value of turbine inlet pressure is obtained where the highest efficiency value is reached. The value of this optimum pressure depends on the saturation pressure value of each working fluid at the evaporator outlet temperature. Working fluids with a low saturation pressure will have an optimum pressure value at low pressure. In contrast, working fluid with a higher saturation pressure will have higher optimum pressure value.

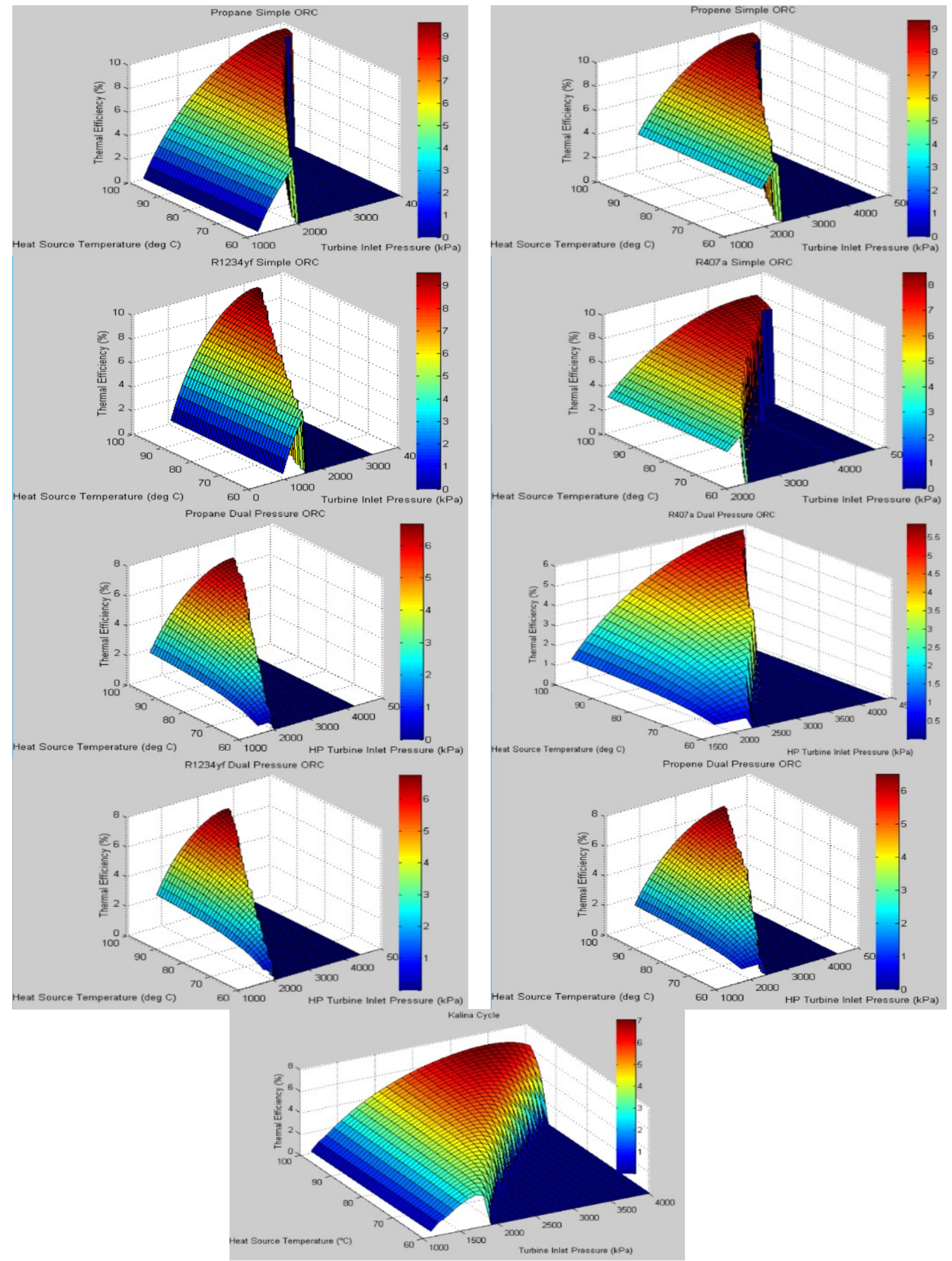

Fig.3.Cycle Efficiency for different Turbine Inlet Pressureand Heat Source Temperature 
For heat source temperature of $95^{\circ} \mathrm{C}$, the highest efficiency value is obtained on ORC simple configuration followed by Kalina and Dual-Pressure ORC. For ORC, the working fluid with the best efficiency value is R1234yf, followed by propane, propene and $\mathrm{R} 407 \mathrm{a}$.

For propane, propene and R1234yf working fluids, there is no decrease in efficiency when turbine inlet pressure continue to increase. The increase will be limited by the vapor fraction of the working fluid after passing through the evaporator. For case of propane, propene and R1234yf, the optimum pressure is reached when the fluid vapor fraction value is 1 . As for the Kalina cycle and the working fluid of R407a with both ORC configuration, there is an optimum pressure when the efficiency value reaches the peak which is $4400 \mathrm{kPa}$ for R407a Simple ORC, $4200 \mathrm{kPa}$ for Dual Pressure $\mathrm{ORC}$ and $3100 \mathrm{kPa}$ for Kalina Cyle.

Cycles with ORC simple configurations have greater efficiency values than Kalina cycle or dualpressure ORC. This is because in the simple ORC, the fluid expansion occurs in a high pressure. High pressure expansion causes arise in power generated. High pressure expansion, in general, results in greater maximum cycle efficiency due to higher delta enthalpy between the inlet and outlet turbine condition.

\subsection{Heat Source Temperature Variations}

Figure 3 shows a three-dimensional graph which illustrates the effect of the temperature of the heat source and the turbine inlet pressure on the thermal efficiency of each working fluid of each cycle. Variations are temperature level with a pinch temperature value in the evaporator of $5^{\circ} \mathrm{C}$. With a set of $5^{\circ} \mathrm{C}$ pinch temperatures, the evaporator output temperature will be less $5^{\circ} \mathrm{C}$ from the temperature of the heat source for each heat source temperature level. Saturated pressure at the evaporator exit temperature of each working fluid will affect the maximum pressure that the working fluid can achieve in order to become vapor phase. The value of this maximum pressure will affect the efficiency, the lower the saturation pressure, the higher the efficiency can be achieved from the working fluid. Efficiency value of the cycle will increase as the temperature of the heat source increases. However, the increase in efficiency that is influenced by the rise of heat source temperature is not significant compared to the increase of efficiency due to the increase of pressure. This is because arise in the temperature of the working fluid will only result in a shrinking dome distance between the saturated liquid point and the saturated vapor in the T-s diagram, so the energy required to evaporate the fluid will be less. However, it is also followed by more heat coming into the system, thus making the efficiency of the cycle not rising significantly.

The temperature of a hot spring ranged from $60^{\circ} \mathrm{C}$ to $99^{\circ} \mathrm{C}$. Each hot spring temperature level with pinch temperature value of $5^{\circ} \mathrm{C}$ causes turbine inlet temperature difference. In general, turbine inlet temperatures will be $5^{\circ} \mathrm{C}$ lower than the temperature of the heat source due to pinch temperature value constraints. As shown in Figure 4,each temperature level of heat source will reach certain maximum efficiency for each configuration and each working fluid. The differences in maximum efficiency that can be achieved for each temperature level is due to difference in

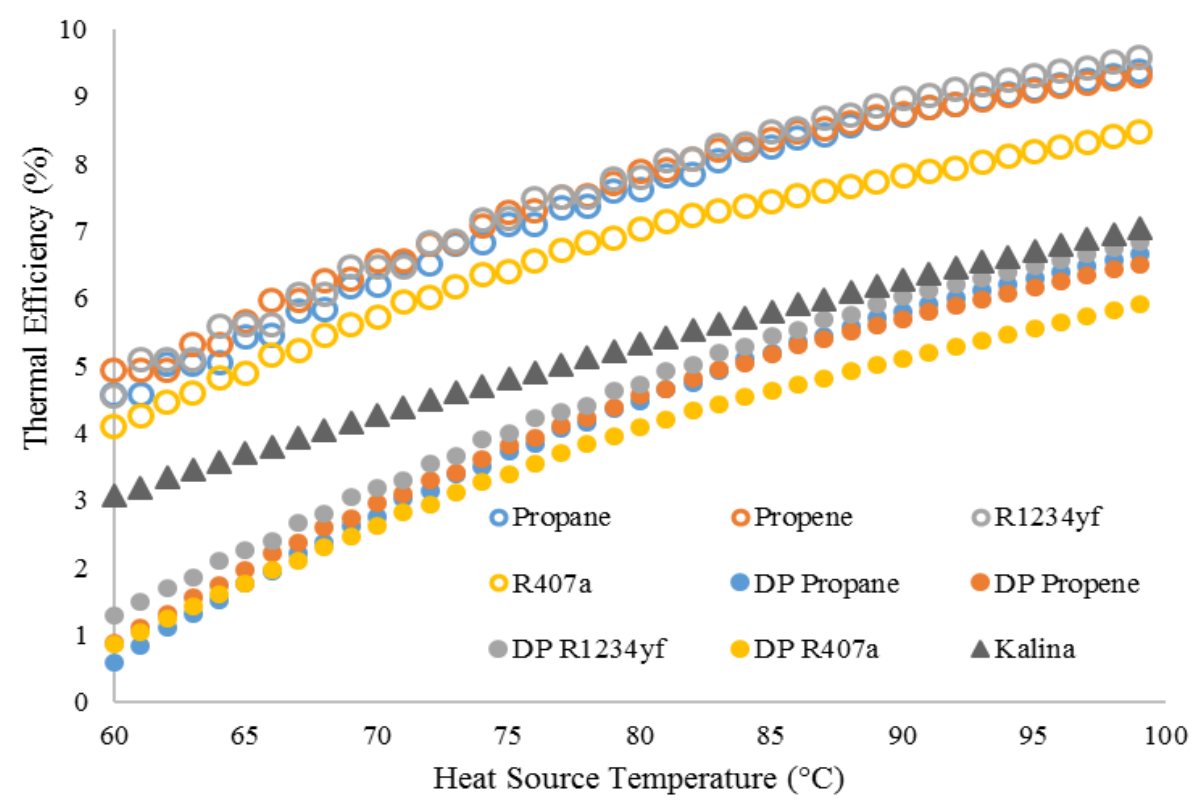

Fig. 4. Cycle Efficiency for different Turbine Inlet Pressureand Heat Source Temperature

performed to produce the maximum efficiency.

Each temperature level of the heat source will produce a maximum efficiency at a certain pressure. This pressure, in each configuration, in general, will be worth the highest pressure that can be achieved at a saturation pressure for each working at turbine inlet temperature. However, there are some performance ranking differences for certain level of heat source temperature. The simple ORC has the best efficiency value for each temperature range. The kalian cycle has 


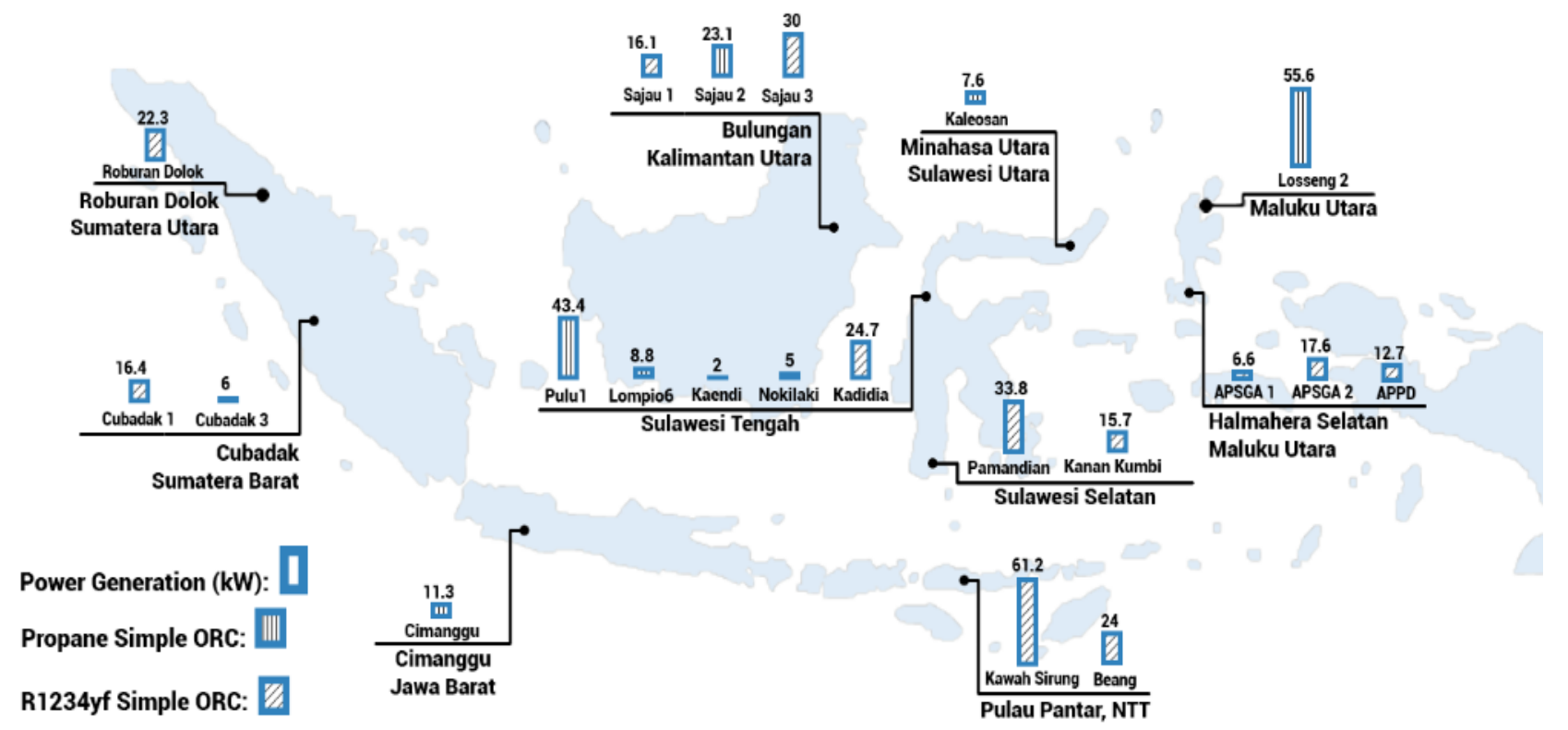

Fig. 5. Power Generation Potential for Hot Spring in Indonesia?

thermal efficiency under simple ORC, followed by a dual-pressure ORC configuration. However, the working fluid with the greatest efficiency for each temperature range is not fixed. In general, R1234yf has a greater efficiency than other working fluids. The propene produces the second highest efficiency, the third-order Propane, and R407a in fourth. But, at the temperature range of $91{ }^{\circ} \mathrm{C}-99^{\circ} \mathrm{C}$ propane efficiency is better than propene.

Working fluid R1234yf with Simple ORC configuration can produce better efficiency than configuration and other working fluid, especially in temperature range $83^{\circ} \mathrm{C}$ to $99^{\circ} \mathrm{C}$. Depends on the heat source temperature level, in general, the best working fluids are R1234yf and propene. Detail performance on each heat source temperature level can be seen in Figure 4.

\subsection{Potential Power Capacity of Indonesia's Hot Spring Sources}

In Indonesia there are various locations of hot spring characteristic varies depends on location, temperature and flow rate or heat duty. Table 5 shows hot spring location, temperature, mass flow rate and heat data. "

The majority of hot spring sources which is potential to be converted into electricity are located in Sulawesi and Maluku. This is because Sulawesi and Maluku region lies in the ring of fire which means many tectonic plates and volcanoes. The existence of a volcano contains a source of heat under the earth surface. The heat source beneath the surface of the earth brings about a geothermal reservoir, which results in the many geothermal manifestations that appear on the surface. Heat duty of hot spring sources ranged from $69 \mathrm{kWt}$ to $1,030 \mathrm{kWt}$
Table 5.Indonesia's Hot Spring Data and Electric ity Generation Potential

\begin{tabular}{|c|c|c|c|c|}
\hline Location & $\begin{array}{c}\text { Temp } \\
\left({ }^{\circ} \mathbf{C}\right)\end{array}$ & $\begin{array}{c}\text { Flow } \\
(\mathbf{k g} / \mathbf{s})\end{array}$ & $\begin{array}{c}\text { Heat } \\
\text { Duty } \\
(\mathbf{k W t )}\end{array}$ & $\begin{array}{c}\text { Electricity } \\
\mathbf{( k W e )}\end{array}$ \\
\hline $\begin{array}{c}\text { Robutran } \\
\text { Dolok }\end{array}$ & 91,0 & 1,3 & 320,3 & 22.3 \\
\hline Cubadak 1 & 74,8 & 2,0 & 399,0 & 16.4 \\
\hline Cubadak 3 & 72,7 & 1,0 & 190,7 & 6 \\
\hline Lompio 6 & 77,0 & 1,0 & 197,4 & 8.8 \\
\hline Sajau 1 & 74,5 & 2,0 & 392,3 & 16.1 \\
\hline Sajau 2 & 80,3 & 2,0 & 441,0 & 23.1 \\
\hline Sajau 3 & 85,8 & 2,0 & 487,2 & 30 \\
\hline Nokilaki & 91,0 & 0,3 & 69,3 & 5 \\
\hline Kadidia & 81,6 & 2,0 & 458,6 & 24.7 \\
\hline Kaendi & 73,0 & 0,5 & 98,7 & 2 \\
\hline Kaleosan & 80,0 & 0,7 & 161,7 & 7.6 \\
\hline Losseng 2 & 77,4 & 5,5 & 1032,6 & 55.6 \\
\hline Kawah Sirung & 98,9 & 3,0 & 849,1 & 61.2 \\
\hline Beang & 81,1 & 2,0 & 408,0 & 24 \\
\hline APSGA 1 & 99,0 & 0,5 & 145,7 & 6.6 \\
\hline APSGA 2 & 99,0 & 1,0 & 296,5 & 17.6 \\
\hline APPD & 88,0 & 0,8 & 186,2 & 12.7 \\
\hline Cimanggu & 78,0 & 1,2 & 308,7 & 11.3 \\
\hline Pulu 1 & 78,9 & 4,0 & 905,5 & 43.4 \\
\hline Pamandian & 74,4 & 4,0 & 816,5 & 33.8 \\
\hline Kanan Kumbi & 62,2 & 4,0 & 625,0 & 15.7 \\
\hline
\end{tabular}

The efficiency value of the power generator at heat source is the function of the temperature level and the technology used. Figure 5 shows mapping of hot spring electricity production potential in Indonesia for each hot spring location with best performing technology. To estimate electricity generated in each location, the best performance cycle for each hot spring temperature is used. Using Figure 4, the cycle and the generated power 
can be estimated. Therefore, cycle efficiency in each hot spring location is different.

The power generated at hot spring range from $2 \mathrm{kWe}$ to $61.3 \mathrm{kWe}$. The resulting power depends on temperature and heat. The largest power value in Kawah Sirung, East Nusa Tenggara. At the location of Kawah Sirung, a power generated of $61.3 \mathrm{kWe}$. The least power generated located in Kaendi, Central Sulawesi with only $2.1 \mathrm{kWe}$

\section{Conclusion}

An increase in turbine inlet pressure will result in an increase in the thermal efficiency value. However, the increase in efficiency will reach the optimum pressure at a certain point. After reaching the optimum value at a certain turbine inlet pressure, thermal efficiency will decrease. An increase in the temperature of the heat source results in increase in thermal efficiency value. The Increase in efficiency due to increased turbine inlet pressure is more significant than the increase in heat source temperature.

Hot spring temperature is ranged from $60^{\circ} \mathrm{C}$ to $99^{\circ} \mathrm{C}$. Each temperature level has its own maximum efficiency. The thermal efficiency is ranged between $4.7 \%$ to $9.6 \%$. Higher temperature will have higher thermal efficiency and vice versa. Each temperature level has its own optimum turbine inlet pressure.

Generally, R1234yf and propene with ORC simple configuration has the best performance compared to other working fluid and configurations. However, there are some differences in specific temperature range. No cycle with a specific working fluid always gives the best performance for each temperature level. Indonesia's hot spring sources have potential power capacity ranged between $2.1 \mathrm{kWe}$ to $61.3 \mathrm{kWe}$.

\section{Acknowledgement}

This study is supported by Hibah PITTA DRPM Universitas Indonesia Contract No:849/UN2.R3.1/HKP.05.00/2017

\section{References}

1. G. Pikra, N. Rohmaha, R.I. Pramanaa, A.J. Purwanto, Energy Proced.68, 12 - 21 (2015)

2. G. Holdmann, Final Report: $400 \mathrm{~kW}$ Geothermal Power Plant at Chena Hot Springs, Alaska (Chena Power, LLC, 2007)

3. R. Di Pippo, Geothermal Power Plants: Principles, Applications, Case Studies and Environmental Impact (Elsevier, 2012)

4. C. E. C. Rodríguez, J. C. E. Palacio, O. J. Venturini, E. E. S. Lora, V. M. Cobas, D. M. dos Santos, F. R. L. Dotto, V. Gialluca,Appl. Therm. Eng.52, 109-119 (2013)

5. R. Di Pippo, Geothermics 33, 565-586 (2004)

6. Z. Shengjun, W. Huaixin, G. Tao, Applied. Energy 88, 2740-2754 (2011)

7. Walraven, D., Laenen, B., D'haeseleer, W. Energy Conv\& Mgmt. 66, 220-233 (2013)

8. N, Oscar, F. Cideos. Power Production Using LowTemperature Heat Sources In El Salvador (Geothermal Training Programme, Iceland: 2012)

9. Y.Z. Wang, J. Zhao, Y. Wang, Q.S. An, Appl. Therm. Eng., (to be published, 2016)

10. N. Shokati, F. Ranjbar, M. Yari. Renew. Energy 83, 527-542 (2015) 